\title{
Patients' fear of genetic discrimination by health insurers: the impact of legal protections
}

Mark A. Hall, JD and Stephen S. Rich, PhD

\begin{abstract}
Purpose: The impact of laws restricting health insurers' use of genetic information has been assessed from two main vantage points: (1) whether they reduce the extent of genetic discrimination and (2) whether they reduce the fear of discrimination and the resulting deterrence to undergo genetic testing. A previous report from this study concluded that there are almost no well-documented cases of health insurers either asking for or using presymptomatic genetic test results in their underwriting decisions, either before or after these laws, or in states with or without these laws. This report evaluates the perceptions and the resulting behavior by patients and clinicians. Methods: A comparative case study analysis was performed in seven states with different laws respecting health insurers' use of genetic information (no law, new prohibition, mature prohibition). Semistructured interviews were conducted in person with five patient advocates and with 30 experienced genetic counselors or medical geneticists, most of whom deal with adult-onset disorders. Also, multiple informed consent forms and patient information brochures were collected and analyzed using qualitative methods. Results: Patients' and clinicians' fear of genetic discrimination greatly exceeds reality, at least for health insurance. It is uncertain how much this fear actually deters genetic testing. The greatest deterrence is to those who do not want to submit the costs of testing for reimbursement and who cannot afford to pay for testing. There appears to be little deterrence for tests that are more easily affordable or when the need for the information is much greater. Fear of discrimination plays virtually no role in testing decisions in pediatric or prenatal situations, but is significant for adult-onset genetic conditions. Conclusion: Existing laws have not greatly reduced the fear of discrimination. This may be due, in part, to clinicians' lack of confidence that these laws can prevent discrimination until there are test cases of actual enforcement. Ironically, there may be so little actual discrimination that it may not be possible to initiate good test cases.
\end{abstract}

Genetics in Medicine, 2000:2(4):214-221.

Key Words: law, health insurance, discrimination, genetics, ELSI

Since 1991, more than half of the states have enacted laws that restrict or prohibit insurers' use of genetic information in pricing, issuing, or structuring health insurance, and similar legislation has been pending in Congress for several years. ${ }^{1,2}$ This wave of legislation was prompted by a number of documented cases of employers and of health, life, and disability insurers using new-found genetic information to deny coverage, raise rates, or limit the extent of coverage. ${ }^{3-t}$ Fear of genetic discrimination of this sort was shown to factor strongly into patients' and family members' decisions and concerns about undergoing genetic testing. ${ }^{7}$ These laws are intended to achieve two kinds of social benefit: (1) to prevent unfair use of genetic information, however accurate that use might be as a source of underwriting information and (2) to encourage

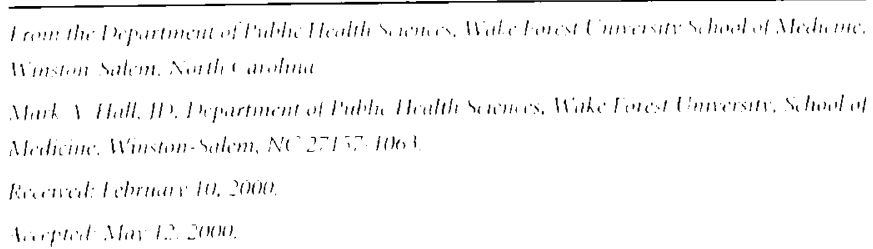

more genetic testing for purposes of research, prevention, treatment, and family planning.

In a previous report assessing the first purpose, ${ }^{8}$ we concluded that there are almost no well-documented cases of health insurers either asking for or using presymptomatic genetic test results in their underwriting decisions, either before or after these laws, or in states with or without these laws. In this report, we assess the second purpose. If it is to provide independent support for these laws, it requires careful evaluation. Fear of insurance discrimination is only one of many factors that potentially influence testing decisions. ${ }^{9.10}$ Therefore, reducing this fear may not increase actual willingness to be tested. Moreover, legal measures may not be the most effective means to reduce fear, especially if they are not well publicized or accurately understood. Similar concerns relating to HIV testing led to various confidentiality and anonymity laws, but these have not promoted testing as strongly as was hoped or expected."

A crucial feature of the genetic discrimination statutes is that they typically do not prohibit the use of genetic information from any and all sources. Instead, they target only information 
derived from genetic tests. Thus, they usually still allow insurers to consider family history of disease and they allow insurers to underwrite based on observed clinical signs and symptoms. A typical statute prohibits health insurers from using only the results of presymptomatic genetic tests. ${ }^{12,13}$ However, we broaden our definition of "genetic discrimination" to capture the common sense, rather than a legal, definition of this term. This focus is whether patients' fear of insurance discrimination deters them from having genetic tests, so that the relevant definition of discrimination is any adverse impact on the ability to obtain, afford, or keep insurance, resulting from a genetic test or from genetic counseling. Although presymptomatic testing is the primary focus, this is not the exclusive focus, because genetic test results can have negative consequences for insurability even for people with clinical symptoms or current disease. Genetic tests might produce a diagnosis of symptoms that is more troubling than the symptoms themselves, or they can identify a mild disease state that is not readily observable from symptoms.

In this report, the focus is limited to genetic information from testing, rather than from family history or disease symptoms, and to concerns about health insurance rather than life or disability insurance. Information from genetic testing is the most relevant point of concern, because these laws are meant to remove the major source of concern that deters people from undergoing genetic testing. Health insurance, rather than other insurance, is the primary concern for most individuals, and it is at the point of deciding whether to undergo genetic testing that this concern has the greatest impact. Accordingly, this report assesses how these legal protections have affected perceived risks of genetic discrimination by health insurers and whether they have encouraged more patients to undergo testing.

\section{MATERIALS AND METHODS}

Details of the study methodology are discussed elsewhere. ${ }^{8}$ Briefly, a comparative case study analysis was performed in seven states (Colorado, Florida, Iowa, Minnesota, New Mexico, North Carolina, Ohio) that were selected to pair similar states with and without laws prohibiting use of genetic information in health insurance. (Six of these seven states were the primary focus of this multiple case study; North Carolina played a secondary role because it was used only to field test interview guides and techniques.) Because legislative activity was ongoing throughout this study, the initial selection and pairing was not wholly successful. Three states initially classified as lacking these laws adopted them in 1997, the year after the study was designed. Therefore, groupings of states were compared according to whether they had mature laws (CO, $\mathrm{MN}, \mathrm{OH}$, all enacted in 1995 or earlier), recent laws (NM, FL, NC), or no law (Iowa). Also, the focus across all of the states was whether perceptions and behaviors differed before and after enactment of these laws.

In each of the primary study states, representatives from the Department of Insurance, most of the major health insurers, most of the major medical centers that perform clinical genetics, and from 3 to 6 insurance agents specializing in health insurance were systematically interviewed. In total, 12 regulators, 35 employees of 23 insurers, 30 insurance agents, and 29 genetic counselors or medical geneticists were interviewed. In addition, five patient advocates and one medical director from a genetic testing firm were also interviewed. Most of these interviews were conducted in-person, one-on-one, and lasted an hour. Some agent interviews were conducted by telephone and some interviews lasted only 15-30 minutes or were conducted with groups of 2-4 subjects. The interviews were semistructured and in-depth based on an interview guide, but discussions were free-ranging and the coverage of topics varied. Also, various sources of documentary information were collected, including: informed consent forms and patient information brochures used by medical geneticists; published articles in academic journals and the popular press about genetic discrimination; and unpublished studies based on surveys done at genetic clinics.

The multiple sources of information and data were analyzed using both qualitative and quantitative techniques. The principal qualitative technique was content analysis of interview transcripts, notes, and informed consent forms. Using triangulation, ${ }^{14}$ patterns of concordance and discordance were determined for each of the following issues: patients' perceptions of the risk of genetic discrimination; the impact these fears have on decisions to undergo testing; counselors' views about whether the new legal protections adequately address these fears; and whether these protections are likely to alter patients' decisions about whether to undergo beneficial genetic testing.

\section{RESULTS}

\section{Patients' perceptions of the risk of genetic discrimination}

Perceptions prior to counseling

Almost all counselors interviewed (92\%) stated that adult patients seeking testing for presymptomatic conditions approach genetic testing with at least some awareness and concern about the potential for insurance discrimination, and most counselors $(67 \%)$ said adult patients have a high level of concern (Table 1). Only two counselors ( $8 \%$ ) indicated their patients have little or no awareness or concern. These counselors explained that most patients hear about insurance discrimination from sources in the news media (such as Parade Magazine, the Ladies' Home Journal) and various television news programs. Knowledge and concern by patients considering testing for Huntington's disease is especially acute. Several counselors explained that this may be due to the active role of the Huntington's Disease Society of America in informing its membership of this concern. Other counselors, however, suggested that the concern among Huntington's patients may come from their own experiences with affected family members.

These attitudes contrasted sharply with counselors in pediatric or prenatal genetic counseling, where all four of the coun- 
Table 1

Counselors' views on insurance discrimination for adult-onset conditions

\begin{tabular}{lc}
\hline & $\begin{array}{c}\text { Percent of } \\
\text { Counselors* }\end{array}$ \\
\hline Level of patients' concern about discrimination & 67 \\
High & 25 \\
Limited & 8 \\
None & \\
How often discrimination is discussed as a risk of & \\
$\quad$ testing & 16 \\
Routinely & \\
Occasionally & 59 \\
Realm in which clients are concerned about & 18 \\
$\quad$ discrimination & 18 \\
Health insurance only & 5 \\
and life insurance & \\
and employment & \\
and disability insurance & 38 \\
No. of patients who decline testing due to & \\
insurance discrimination concerns &
\end{tabular}

selors stated their patients have no prior awareness or concern about genetic discrimination. This result is confirmed by a 1997 mail survey of 272 genetic counselors, which found that counselors who see mostly adult patients view their patients as more concerned about privacy and discrimination issues, and are more likely to discuss these concerns with their patients, than are counselors who see mostly pediatric or prenatal patients. ${ }^{15}$

\section{Views conveyed during counseling}

For patients who considered genetic testing without prior knowledge or concern about discrimination, counselors were questioned whether they alerted them to the possibility of genetic discrimination, and whether this was a primary source of patients' information and concern. For pediatric and prenatal situations, counselors rarely raise insurance discrimination as a risk of testing. This is not perceived as an appropriate concern for patients who come to counseling in a "crisis atmosphere." For these parents, insurance problems are considered the "last thing" on their minds, because they are more concerned about the health of their child or a potential birth defect. Prenatal and pediatric counselors identified insurance discrimination as an insignificant risk because the parents who have the insurance are not the affected individual, and counselors are confident that the law protects newborns with congenital defects and prohibits insurers from discriminating against parents based simply on their carrier status. Only 1 of 14 informed consent forms reviewed mentions insurance discrimination as a risk of testing, related to pediatric, prenatal, or generic genetic conditions (Table 2).

For adult patients, the situation is in sharp contrast. The great majority of counselors, $(21$ of $25,84 \%$ ) routinely discuss the potential for insurance discrimination as a risk of genetic testing (Table 1). This issue is stressed in the leading academic articles and professional practice guidelines about informed consent to genetic testing for adult-onset conditions. ${ }^{16-20} \mathrm{~A}$ review of 11 informed consent forms that address adult-onset genetic conditions disclosed that seven $(64 \%)$ include insurance discrimination as a potential risk of genetic testing (Table 2). A similar study found 6 of 7 informed consent forms used for breast cancer testing warn about insurance risks. ${ }^{21}$ In our survey, three informed consent forms contained only brief mention (or mild notice) of this risk, such as "risks of testing include possible difficulties with employment or insurance," and "I have been explained the potential for insurance discrimination if I choose to inform my insurance company about my decision to pursue genetic testing." However, the language in 4 of the 11 forms contained lengthy and strongly-worded warnings, such as:

"If you learn that you have a genetic predisposition to breast and/or ovarian cancer, you will have knowledge that you may be forced to disclose to third parties. For example, as insurance companies learn more about hereditary risk for cancer, they may ask about the results of genetic tests of those who have or apply for coverage. In most states, life and disability insurers may ask such questions and use the answers in underwriting decisions. . Knowledge that you have a genetic predisposition to breast and/or ovarian cancer may compromise your ability to obtain or maintain insurance coverage."

Most counselors reported averaging about 15 minutes (of a 1-2 hour session) covering genetic discrimination concerns, although some average only a few minutes, depending on the level of concern expressed by their patients. They explained that this practice is part of their training and a result of the strong culture of informed consent in the genetic testing community. ${ }^{22}$ The four counselors who do not always raise this issue with adult patients still said they do so occasionally, depending on situational factors (such as the documented potential for discrimination for the particular genetic condition as well as the patient's current insurance situation).

When these counselors raise insurance discrimination concerns, a large majority ( 16 of 22 ) note that the actual incidence of discrimination is very low, that the risks are significant only

\section{Table 2}

Discussion of discrimination risks in informed consent forms for genetic testing

\begin{tabular}{lcc}
\hline Degree of Emphasis & \% of Adult-onset Forms & \% of Other Forms \\
\hline Lengthy/strong & $(\mathrm{n}=11)$ & $(\mathrm{n}=14)$ \\
Brief/mild & 36 & 0 \\
None & 27 & 7 \\
\hline
\end{tabular}


for certain types of insurance, or that there are various legal protections. Several counselors reported attempting to reassure patients by calming fears and describing the various confidentiality measures that are taken to help protect against this risk. However, all of these counselors tell patients the risk should be taken seriously for adult onset conditions and they view their primary objective as alerting patients to this potential risk. Moreover, only a few of these counselors mention the potential positive uses of genetic test results, such as showing that someone suspected of having a genetic condition based on family history does not, in fact, have the gene. ${ }^{15}$

Counselors explained that they reassure patients in other ways, by using several measures that enhance the secrecy of genetic test results. These measures include discretion in documenting the purpose of a visit and where test results are sent. A visit is described as screening for cancer rather than genetic testing, and the test results are often not sent to the referring physician unless directed by the patient. Even then, counselors often advise the patient's regular physician to not place the results in the medical record. Similarly, most genetic clinics maintain separate "shadow" files that keep records apart from the hospital's medical records. These measures are intended to minimize the possibility that insurers learn of testing or test results from claims for reimbursement or from routine requests for medical records. The information will come to light only if the insurer knows to specifically request it from the genetic clinic.

\section{Deterrent effects of discriminatory fears}

The reported impact of patients' discrimination concerns on decisions to undergo testing varies for different types of patients. For pediatric and prenatal patients, almost all counselors said that insurance discrimination concerns play no role in decisions about testing, for the obvious reason that, for people who are carrying a baby or have a child with a problem, the urgency of their immediate situation is so great and they are so anxious that they will undergo just about any test they can to find out more specifically what is going on with their child. One physician, however, gave an example of a mother with a family history of thyroid cancer who deferred testing her 2 year old child for a gene defect that is $100 \%$ predictive, because she was a young, single parent who did not expect to remain in the same job and did not want to have this on her record if she needed to obtain different health insurance. Although this physician felt that "real harm" could have resulted from the mother's fear of discrimination because the testing information might have resulted in earlier or more intensive cancer screening, the mother intended to defer the test for only a short while, and the physician suspected the mother was able to obtain the test for free from another physician who was her personal friend.

For adult patients, a number of counselors ( 8 of 21 ) said that discrimination concerns are a major barrier to testing, and that large numbers of their clients decline testing, primarily for this reason (Table 1). All counselors said that when discrimination is a concern, health insurance, rather than life or disability, is the primary concern, and the majority ( 13 of 22 ) said that only health insurance is a concern. Four counselors mentioned lesser concerns over life insurance, one mentioned disability insurance, and four mentioned employment discrimination (Table 1).

A majority of counselors ( 13 of 21 ) said that insurance concerns, while great, do not have much actual impact on patients' final decisions about testing. Four counselors said that only $5-10 \%$ of adult patients decline testing because of discrimination concerns. One experienced counselor explained: "I think [insurance discrimination] is a big fear, but once people make it to the clinic it's not the reason that keeps them from getting tested. Once people decide to have the test, nothing gets in their way. Nothing. Money, nothing." Another said that, "... for Huntington's disease, I think [the proportion of patients who decline testing primarily because of discrimination concerns] is really small. I think that most people have other reasons that they might not want testing and that's just one of the things they add to the pile. I've not had anybody say "I really really want to know, I want to know and I've got a million reasons for knowing but the one reason why I'm not having the test is this [discrimination] issue." The people that were the most concerned about it found a way around it in that they used aliases. I really don't think that anybody is not having Huntington's testing, at least in my experience, solely because of this. . . For cancer, I would say that it's the same. I think it's very low to almost zero... I can't remember anybody that used that as their sole reason. They have all of these other reasons and that just added to the pot. "

Several other counselors explained that patients with prior symptoms have a greater sense of urgency to be tested and they realize that, with a history of disease already well documented, there is little risk that the genetic test itself may worsen their insurability. Thus, it appears that deterrence may be the lowest in the situations where there is the greatest need for testing, and the highest where testing is more discretionary.

Some counselors reported that patients with the greatest reluctance to undergo testing are often family members of the patient and their reluctance is for reasons unrelated to insurance concerns. These reluctant clients are often scheduled by a patient who requires the relative to diagnose a condition, but these members themselves have not sought out genetic testing. These relatives may not want to live with the psychological burden of information about possible future health problems, or for other reasons may be opposed to testing for purely predictive, presymptomatic conditions. Pointing to potential discrimination concerns that are raised in genetic counseling could give them a more socially acceptable reason to decline.

Several counselors reported that discrimination concerns are much less pronounced in research than clinical settings, even though research patients are also ones who are often recruited for testing rather than initiators of testing. The lesser concern in research settings can be explained by several factors. First, testing under research protocols often is not billed to insurers or patients, so the financial barriers are not always present. Also, research records are less likely to become part of 
the medical record and discovered through routine medical underwriting. Finally, research protocols may have "certificates of confidentiality," which provide extensive protection against discovery or use of the information for unapproved purposes. ${ }^{23}$ For these reasons, counselors perceived less risk of discrimination in research settings. However, our review of informed consent forms did not reveal any less attention to discrimination risks in research settings than in nonresearch clinical settings.

Many counselors also explained that the primary barrier posed by concerns over insurance discrimination is not refusal to take the test but reluctance to seek reimbursement from health insurance for the costs of testing and counseling. They thought that the secrecy measures sufficed to protect confidentiality by keeping information about testing out of the medical record and, as a result, notifying an insurer to pay for the procedure would remove this protection. Thus, many patients, with the encouragement or advice of counselors, opt to pay for testing "out of pocket" in order to lessen the risk of discrimination by health insurers. This is the impact most often cited for Huntington's patients.

Several counselors observed that discrimination concerns vary by insurance and socioeconomic status. For instance, people with government health insurance are much less concerned about discrimination (including Medicaid or state-assisted patients and those in the military). Counselors suggested several explanations. People may believe that genetic information is much safer in the hands of government than of private insurers. Some counselors suggested that Medicaid patients are less concerned about theoretical issues of future financial protection because their focus is on immediate needs. Also, counselors noted that patients with more education and better jobs are more likely to seek testing where there is not an immediate medical need, such as predisposition to cancer or carrier status, and that those from higher socioeconomic ranks are more likely to be covered by private insurance and to be more aware of the potential for discrimination.

\section{Impact of legal protections}

Counselors' awareness, knowledge, and views of the law

Most counselors $(80 \%)$ had some awareness of the relevant state law, and virtually all had some awareness that there was a federal law (HIPAA) relating to genetic discrimination by health insurers (Table 3). Although awareness is high, accurate knowledge of the law is not. Only $60 \%$ of counselors had a reasonably accurate understanding of the federal law, and accuracy dropped to $35 \%$ for the state laws (Table 3 ). Of those who misunderstood the state law, almost all (7 of 9) underestimated its degree of protection, and the remainder had only a vague awareness of the state law.

The pattern of knowledge and awareness follows the age of the state law protections. Counselors in states with established laws that were in effect for more than 2 years were much more likely to have some knowledge or accurate understanding of state laws than counselors in states that had enacted their law in
Table 3

Counselors' knowledge of legal protections

Percent of Counselors

$(\mathrm{n}=20)$

Aware of law

State

Federal

95

Accurate understanding of law

State

Federal

60

only the past year or less (Table 4). Six of the seven counselors $(86 \%)$ with accurate knowledge of the state laws were in states with established laws, and all four of the counselors with no awareness of state law were in states with new laws.

When asked about the effectiveness of these legal protections addressing concerns of insurance discrimination, counselors did not feel that the law was sufficiently protective. Overwhelmingly, the most common objection (15 of 21) was that these laws are untested (Table 5). Counselors were concerned that, until test cases are brought and there are definitive rulings from the courts establishing that vulnerable people are in fact protected, there were too many ambiguities and uncertainties for these laws to be reliable.

Aside from the general uncertainty of any law, genetic counselors pointed to a number of specific defects, loopholes, or shortcomings in their particular state laws (Table 5). Some counselors would like to see the law encompass a broader range of genetic information. Seven observed that the law covers only health insurance, six noted it covers only information from genetic testing, and four mentioned that it applies only to presymptomatic situations. Others pointed to jurisdictional defects. Seven observed that the state laws do not protect people who move to another state and seven knew that, because of ERISA preemption, state laws do not protect people in selffunded employer plans. Thus, these counselors would like to see a federal law. Still others pointed to questions about the law's permanence and enforceability. Ohio's law was enacted initially as a moratorium that was due to expire after 10 years, so three counselors were concerned about whether its protections would extend far enough into the future to cover their current clients. (The Ohio statute has since been made permanent, but in theory, any of these laws could be repealed, which would open the question of whether previously acquired infor-

Table 4

Counselors' knowledge of state law, by age of state law

\begin{tabular}{lcc}
\hline & $\begin{array}{c}\text { Some } \\
\text { Awareness }(\%)\end{array}$ & $\begin{array}{c}\text { Accurate } \\
\text { Understanding (\%) }\end{array}$ \\
\hline New law states $(\mathrm{n}=10)$ & 60 & 10 \\
Established law states $(\mathrm{n}=10)$ & 100 & 60 \\
\hline
\end{tabular}


Table 5

Defects in legal protections mentioned by counselors

\begin{tabular}{lc}
\hline Defect & $\begin{array}{c}\text { No. of Counselors } \\
\text { Who Mentioned }\end{array}$ \\
\hline Laws are untested & 15 \\
Laws cover only health insurance & 7 \\
Laws do not apply in other states & 7 \\
Laws do not apply to self-funded plans & 7 \\
Laws cover only genetic testing & 6 \\
Laws cover only presymptomatic testing & 4 \\
Laws can be repealed & 3 \\
Enforcement mechanisms are weak & 2 \\
\hline
\end{tabular}

mation would still be protected; thus, nothing short of a constitutional amendment would appear to address this concern.) Two counselors noted that their state's law does not have a strong or obvious enforcement mechanism, so it is not clear what remedies are available against violators.

\section{The law's impact on perceived risks and on testing decisions}

Legal protections have had little impact on the perceived risks of genetic discrimination, or on patients' decisions to undergo testing. First, these laws have not significantly changed how genetic counselors approach informed consent and their warnings to patients about the risks of discrimination. Although most counselors with knowledge of the state laws mention these laws to patients, few counselors give the legal protections much emphasis, and no counselor is reassuring about the risks of discrimination by health insurers. All warn their clients to some extent. Of the 11 informed consent forms we reviewed that address adult-onset conditions, only two $(18 \%)$ mention any legal protections: one does so only briefly, and the other stresses the laws' inadequacies. Only 3 of 17 counselors ( $18 \%$ ) offer any reassurance based on these legal protections. These counselors give fairly detailed and accurate descriptions of the legal protections, usually in writing, and tailor the discussion to the patient's exact insurance situation (uninsured, individual, group, etc.); the rest view the legal uncertainties and loopholes as too significant to merit any reassurance. All three of those who give at least some reassurance are in states with older laws. Also, a greater proportion of counselors in states with older laws noted the low probability of discrimination than in states with new or no laws [83\% ( 10 of 12) versus $64 \%$ ( 7 of 11 )], suggesting that confidence in and reliance on the law may grow over time.

Among patients, there is little indication the legal protections have had any impact. Counselors' reports about whether patients have prior awareness of the potential for discrimination does not follow any pattern that relates to the pattern of state laws. Similarly, counselors' reports about the impact this concern has on decisions to undergo testing follow no pattern that relates to the state laws. Almost none of the counselors observed any reduction in their patients' concerns about dis- crimination following enactment of these laws, and many noted that patients' concerns have increased recently, most likely due to more widespread publicity about the problem.

\section{DISCUSSION}

In his review of barriers to HIV testing, Burris ${ }^{24}$ warns against elevated hopes about legal protections aimed at complex behavioral and psychological phenomena such as those under study here. He observes that "research and policy literature. . . display a common tendency to treat law as a simple "tool" for influencing the complex behaviors that are seen as the proper subject of the social sciences. . If law does have an influence on behavior, its mechanism is likely to be every bit as complex and worthy of study as any other behavioral influence on those at risk for HIV." So it is with genetic testing. For HIV testing, although numerous studies had suggested that people at risk for AIDS would greatly decrease their rate of testing if confidentiality protections were reduced, when mandatory reporting laws were implemented requiring test results to be sent to public health officials, actual testing patterns did not decline. ${ }^{25}$ Other researchers, however, found that anonymous HIV testing leads to earlier detection and medical intervention. ${ }^{26}$

In order to assume that antidiscrimination laws will increase testing, Burris ${ }^{11}$ explains that there must be confidence in both of the following: (1) discrimination fears are significant and actually deter testing and (2) patients will learn of these legal protections and will see them as sufficiently reassuring to alter their calculus of the net advantages of testing. For HIV testing, Burris documents the weakness of reliable evidence on each of these points. In this study, we found not just an absence of evidence, but considerable contradictory evidence on each of these assumptions.

\section{Fear and deterrence}

A number of researchers have reported from patient surveys that insurance discrimination is one of the primary fears that deter patients from undergoing genetic testing, ${ }^{27-30}$ although other findings indicate the contrary. ${ }^{716,31}$ Studies that survey patients must be taken with some caution, however, because the survey format usually prompts responses to speculative questions about imagined behaviors and motivations, rather than testing actual behavior in response to different circumstances. Our study does not fully correct these flaws. However, our probing interviews with experienced genetic counselors provides an informed and somewhat more objective view of patients' concerns, motivations, and behavior.

Genetic counselors report that insurance concerns differ sharply between prenatal and pediatric settings versus adultonset disorders. Because children are usually well protected by health insurance, and because parents are so concerned about the pressing need to learn more about their children's potential or actual health problems, insurance discrimination is not sufficiently relevant for most counselors to raise as an issue when testing newborns, children, or potential parents. For adult patients, concerns about insurance discrimination are much 
greater, but there is reason to question how strong the actual impact is on decisions to undergo testing. Many counselors we interviewed think that insurance concerns do not rank as highly as the psychological impact of learning one's genetic fate, ${ }^{31,32}$ or they believe this concern is important only when the need for the information is low. Thus, discrimination concerns are often overshadowed by other barriers to testing, or by the pressing need for the information. Other counselors strongly disagree.

The most significant barrier created by discrimination concerns is not outright refusal to take the test, but increased cost, since those who do not trust insurers with the information may still be willing to take the test if they do not have to notify their health insurer, but this requires them to pay for counseling and testing, which can be expensive. Other studies have shown a high level of cost sensitivity in decisions about genetic testing. ${ }^{33,34}$ This may explain, in part, the puzzle over why health insurance is the focus of discrimination concerns, even though the documented record of and potential for discrimination is stronger for life and disability insurance. One explanation is that health insurance is more important to people, but another is that health insurance is what patients and geneticists depend on to pay for testing. The greatest impact, then, appears to be on people with private insurance who consider more discretionary testing.

It is also important to recognize that these views represent only the perspective of those who come in for counseling. Many counselors explained that most of their adult-onset patients already know about the potential for discrimination and so have already considered this and have decided to be tested by the time they come to the clinic. People with the greatest concern about discrimination never call, or they decide after only a brief phone conversation not to come in. Counselors are unable to assess the full impact of discrimination fears from this broader, population-based perspective, but they did offer some evidence that it is significant. One clinic conducts an ongoing survey of people who call the clinic but never come in for counseling, and it finds that insurance discrimination concerns are the primary reason.

These disparate views about the actual impact of insurance discrimination concerns make it difficult to draw any firm conclusions. However, it appears that fear of insurance discrimination has widely varying impact depending on the circumstances of different clinical settings and patient populations. Different people with different genetic conditions have highly differentiated responses. Insurance discrimination is not a deterrent to testing when parents face pressing concerns about the health of their child or fetus. Similarly, patients seeking diagnosis for their own symptoms usually see the immediate need for the information as outweighing the risks of future discrimination, unless the information will not alter very much their course of treatment. Thus, fear of discrimination is often not the dominant reason for declining testing, and, when it is the main reason, the actual harm to the potential patient may not be great.

The impact of discrimination fears appears strongest for those who are being recruited to help a relative, but they are often reluctant for other reasons. ${ }^{35}$ Discrimination concerns also weigh heavily in more marginal situations, where the benefits of testing are less, and discrimination fears convince many patients to not submit the costs of testing to their health insurer. This financial burden adds to the deterrent effect. Nevertheless, most counselors believe that patients with a strong reason for testing are seldom deterred. Since these views are collected from the perspective of genetic counselors, they fail to capture the views of those whose fear is the greatest and therefore never initiate contact with genetic clinics. Finally, it bears emphasis that the variation in these responses has no apparent relation to the pattern of laws among these study states.

\section{Reassurance through legal protections}

Where discrimination fears actually deter testing, there is little reason to believe that the legal protections so far have offered much reassurance or have altered testing decisions. These laws provide little reassurance because counselors do not perceive them as significantly reducing the actual risk of discrimination, or they do not yet have sufficient confidence in these laws. These protections have not received nearly as much publicity as has the potential risk of discrimination, so patients' primary source of information about these laws is the genetic counselor. Genetic counselors use the informed consent and counseling process to alert adult patients to the risks of insurance discrimination. In doing so, although they are not alarmist, they are also not very reassuring. Counselors have good knowledge of these laws, which they usually mention during counseling. Indeed, their awareness is somewhat better than that of the insurance agents and underwriters. ${ }^{8}$ Counselors, however, continue to place more stress on alerting patients to these potential risks than on reassuring them of the legal protections. Rather than rely on the law, counselors are more inclined to take practical measures to protect the secrecy of genetic information, such as maintaining shadow charts, advising patients to pay out of pocket, and counseling patients about how to keep the information out of their regular medical records.

\section{Public policy responses}

From several vantage points, it appears these laws have failed in their goal of encouraging more genetic testing. How might public policy respond to this failure? One remedy is legal. High profile enforcement actions could be initiated under the existing laws to demonstrate their effectiveness and increase confidence in them, but there may be too few instances of actual discrimination to find any good test cases. Existing laws could be made greatly more protective, but the skepticism with which geneticists and others view the insurance industry suggests that this will not alter patients' and counselors' attitudes unless the reforms are truly radical. Federalizing the state laws will still leave many of the gaps and loopholes identified by genetic counselors. Even broadening these laws to prohibit the use of predictive medical information of any kind ${ }^{4}$ would still leave in place considerable uncertainty about when conditions are unexpressed and information is truly presymptomatic. Nothing short of either national health insurance or the complete elimination of medical underwriting would appear to fundamentally address these concerns. 
Another remedy is educational. Burris ${ }^{11}$ observes for HIV testing that "it is possible. . . that perceived risk may be reduced without reducing the actual risk. If the goal is to encourage more testing, then perceived risk, rather than actual risk, must be the primary goal." For genetics, this is even more so true because the actual risk may be so low that further significant reduction is not easily achievable. Thus, if the documentation is believable of a very low incidence and potential for genetic discrimination by health insurers, ${ }^{8}$ then the focus could be shifted from eliminating all risk to increasing more accurate perception of the risk. A prime target for this perception is genetic counseling and informed consent policies for genetic testing. In situations where the documented and potential risks are very low, medical genetics might drop this area of concern altogether from discussions with patients. However, not discussing discrimination concerns would fail to offer the reassurance that concerned patients may need. As Reilly ${ }^{36}$ suggests, informed consent and counseling could emphasize the near absence of any documented harm resulting from genetic testing, and the very low potential for this in view of the mounting legal protections-rather than emphasizing just the opposite.

Naturally, the legal and the educational remedies are not mutually exclusive, and indeed might be mutually reinforcing. Federalizing the existing state laws would increase geneticists' confidence in legal protections against discrimination. A prominent federal law would help to counter widespread and exaggerated publicity of discrimination risks. Moreover, such a law would not alter existing practices by health insurers or remove an essential underwriting tool, since state laws and industry practices already discourage insurers from using presymptomatic genetic information. Therefore, people on both sides of the current legislative debate will find support for their positions in our findings. By outlining these possible interpretations and applications, we do not mean to endorse any one or more of these positions, but instead to highlight how these findings might inform ethical and political debate.

\section{Acknowledgments}

This research was supported by NIH grant R01- HG01662 from the National Human Genome Research Institute. Also participating in this research were Janice Lawlor, MPH, Elliot Wicks, PhD, Craig Richardson, $\mathrm{PhD}$, and Jeannette Bensen, MS, all of whom were essential to the project.

\section{References}

1. Mulholland W, Jaeger A. Genetic privacy and discrimination: a comprehensive survey of state legislation. Jurimetrics / 1999;9:1-10

2. Colby J. An analysis of genetic discrimination legislation proposed by the 105th Congress. Am J Law Med 1998:24:443-480.

3. Billings PR, Kohn MA, de Cuevas M, Beckwith I, Alper IS, Natowicz M. Discrimination as a consequence of genetic testing. Am I Hum Gent 1992:50:476-482.

4. Alper J, Geller LN, Barash CI, Billings PR, Laden V, Natowicz M. Genetic discrimination and screening for hemochromatosis. / Public Health Policy 1994;15:345-358.

5. Hudson KL, Rothenberg KH, Andrews LB, Kahn MJE, Collins FS. Genetic discrimination and health insurance: an urgent need for reform. Science 1995;270:391-393.

6. Geller LN, Alpers IS, Billings PR, Barash CI, Beckwith I, Natowicz N. Individual, family, and societal dimensions of genetic discrimination: a case study analysis. $\mathrm{Sc}_{\mathrm{i}} \mathrm{i}$ Eng Ethics 1996;2:71-88.
7. Lapham V, Kozma C, Weiss I. Genetic discrimination: perspectives of consumers. Sicince 1996;274:621-624.

8. Hall MA, Rich SS. The impact on genetic discrimination of laws restricting health insurers' use of genetic information. Am / Hum Genet 2000:66:293-307.

9. Ulrich CM, Kristal AR, White E, Hunt JR, Durfy SF, Potter JD. Genetic testing for cancer risk: a population survey on attitudes and intention. Community Genetics 1998;1:213-222.

10. Quaid K, Morris M. Reluctance to undergo predictive testing: the case of Huntington's disease. Am / Med Genet 1993;45:41-45.

11. Burris S. Law and the social risk of health care: lessons from HIV testing. Albany Law $\operatorname{Rev} 1998 ; 61: 831-895$

12. Hall MA. Insurers' use of genetic information. Jurimetrics / 1996;37:13-22

13. Hall MA. Restricting insurers' use of genetic information: a guide to public policy. $N$ Am Actuarial / 1999;3:34-49.

14. Mays N, Pope C. Rigour and qualitative research. BM/ 1995;311:109-112.

15. Hoyle CL. Discussion of genetic discrimination issues by genetic counselors and their clients [Thesis]. Cincinnati: University of Cincinnati, Department of Pediatrics, Genetic Counseling Program, 1997.

16. Bernhardt BA, Geller G, Strauss M, Helzlsouer K1, Stefanek M, Wilcox PM, Holtzman NA. Toward a model informed consent process for BRCAl testing: a qualitative assessment of women's attitudes. Genetic Couns 1997;6:207-222.

17. Reilly PR, Boshar MF, Holtzman SH. Ethical issues in genetic research: disclosure and informed consent. Nat Genet 1997;15:301-305.

18. National Society of Genetic Counselors. Predisposition genetic testing for late-onset disorders in adults. JAMA 1997:278:1217-1220.

19. Geller G, Botkin IR, Green MJ, Press N, Biesecker BB, Winfond B, Grana G, Daly $M B$, Schneider $K$, Kahn MI. Genetic testing for susceptibility to adult-onset cancer: the process and content of informed consent. JAMA 1997;277:1467-1474.

20. American Society of Clinical Oncology. Genetic testing for cancer susceptibility. J Clin Oncol 1996;17:1730-1736.

21. Durfy SI, Buchanan TE, Burke W. Testing for inherited susceptibility to breast cancer: a survey of informed consent forms for BRCAl and BRCA2 mutation testing. Am / Med Genet 1998;75:82-87.

22. Biesecker BB. Future directions in genetic counseling: practice and ethical considerations. Kenncdy Inst Ethics / 1998:8:145-160.

23. Clayton EW. Informed consent and genetic research. In: Rothstein MA, editor Genetic secrets: protecting privacy and confidentiality in the genetic era. New $\mathrm{Ha}_{\mathrm{a}}$ ven: Y'ale University Press, 1997:127-136.

24. Burris S. Driving the epidemic underground: a new look at law and the social risk of HIV testing. AIDS \& Public Policy / 1997;12:66-72.

25. Nakashima A, Horsley R, Frey RL, Sweeney PA, Weber IT, Fleming PL. Effect of HIV reporting by name on use of HIV testing in publicly funded counseling and testing programs. JAMA 1998;280:1421-1426.

26. Bindman $\mathrm{AB}$, Osmond $\mathrm{D}$, Hecht FM, Lehman $\mathrm{S}, \mathrm{V}$ ranizan $\mathrm{K}$, Keane $\mathrm{D}$, Reingold $\mathrm{A}$. Multistate evaluation of anonymous HIV testing and access to medical care: Multistate Evaluation of Surveillance of HIV (MESH) Study Group. JAMA 1998;280: $1416-1420$.

27. Lynch HT, Watson P, Tinley S, Snyder C, Durham C, Lynch I, Kirnarsky Y, Serova O, Lenoir G, Lerman C, Narod S. An update on DNA-based BRCAI/BRCA2 genetic counseling in hereditary breast cancer. Cancer Genet Cytogenet 1999;109:91-98.

28. Wingrove KJ, Norris J, Barton PL. Hagerman R. Experiences and attitudes concerning genetic testing and insurance in a Colorado population: a survey of families diagnosed with fragile $X$ syndrome. Am / Med Genet 1996;64:378-381.

29. Lerman $C$, Schulman $K$, Hughes $C$, Gomez-Caminero A, Bonney G, Gold $K$. Trock B, Main D, Lynch J, Fulmore C, Synder C, Lemon SI, Conway T, Tonin P, Lenoir G, Lynch $\mathrm{H}$. BRCAl testing in families with hereditary breast-ovarian cancer: a prospective study of patient decision making and outcomes. JAMLA 1996;275:1885-1892.

30. Health and Human Services. Health insurance in the age of genetics. Health and Human Services Department, July, 1997.

31. Codori AM, Brandt 1. Psychological costs and benefits of predictive testing for Huntington's disease. Am / Mcd Genet 1994;54:174-184

32. Uhlmann W, Ginsburg D, Gelehrter TD, Nicholson I, Petty EM. Questioning the need for anonymous genetic counseling and testing. Am / Hum Gent 1996;59:968-970.

33. Chaliki H, Loader S, Levenkron I, Logan-Young W. Hall WI, Rowley PI. Women's receptivity to testing for a genetic susceptibility to breast cancer. Am / Public Health 1995;85:1133-1135

34. Rowley PT, Loader S, Kaplan RM. Prenatal screening for cystic fibrosis carriers: an economic evaluation. Am J Hum Genet 1998;63:1160-1174.

35. Baty BI, Venne VL, MiDonald I, Croyle RT, Hall C, Nash IE, Botkin IR. BRCAI testing: genctic counseling protocol development and counseling issues. Genetic Couns 1997;6:223-244.

36. Reilly PR. Genetic discrimination. Washington, DC: American Enterprise Institute for Public Policy Research, 1997. 